\title{
Angoulême - Abbaye Saint-Cybard
}

\section{Mélanie Chaillou}

Édition électronique

ISSN : 2114-0502

Éditeur

Ministère de la culture

Référence électronique

Mélanie Chaillou, "Angoulême - Abbaye Saint-Cybard », ADLFI. Archéologie de la France - Informations [En ligne], Poitou-Charentes, mis en ligne le 01 mars 2008, consulté le 02 mai 2019. URL : http:// journals.openedition.org/adlfi/654

Ce document a été généré automatiquement le 2 mai 2019.

(c) Ministère de la Culture et de la Communication, CNRS 


\title{
Angoulême - Abbaye Saint-Cybard
}

\author{
Mélanie Chaillou
}

Identifiant de l'opération archéologique : 204765

Date de l'opération : 2008 (EX)

Inventeur(s) : Chaillou Mélanie (HADES)

Le nouveau projet d'aménagement de l'îlot Charbonneau à Angoulême, propriété de la Mairie, envisage la création d'un complexe de services par la société Vinci Immobilier.

Cet îlot se situe à flanc de coteau, à la jonction de la rue de Bordeaux au nord (du côté de la Charente) et de l'avenue de Cognac au sud. Il était autrefois occupé par une abbaye dont des fouilles, effectuées dans les années 1986-1988, attestent l'existence depuis au moins la seconde moitié du VI ${ }^{e} \mathrm{~s}$. Détruite par les Normands à la fin du IX ${ }^{\mathrm{e}} \mathrm{s}$., l'abbaye Saint-Cybard semble avoir été reconstruite dans la première moitié du XI ${ }^{\mathrm{e}} \mathrm{s}$. Très endommagée pendant la guerre de Cent Ans, de nouveaux travaux y sont engagés dans la seconde moitié du XV ${ }^{\mathrm{e}} \mathrm{s}$., puis au XVII ${ }^{\mathrm{e}} \mathrm{s}$., après les dégâts occasionnés par les guerres de Religion. Enfin, après la Révolution Française et sa vente comme bien national, l'abbaye est presque totalement rasée, à l'exception du rez-de-chaussée de la partie ouest sur laquelle est construite une papeterie au début $\mathrm{du}$ XIX ${ }^{\mathrm{e}} \mathrm{s}$., alors que la partie orientale, où se trouvait le cloître, devient le siège de brasseries (à l'emplacement actuel du CNBDI).

C'est donc un agencement complexe d'architectures allant du Moyen Âge à l'époque contemporaine qui occupe désormais cet îlot, les parties les plus anciennes se trouvant au rez-de-chaussée et ponctuellement aux premier et deuxième étages. Les élévations d'une grande partie des bâtiments ont été étudiées en 2002 par Marie-Êve Scheffer, mais cette étude - pourtant très avancée - est restée incomplète. La société Hadès a alors été choisie pour compléter l'analyse du bâti du mur ouest de l'espace que Marie-Êve Scheffer avait identifié comme étant l'infirmerie (MUR 100), et effectuer quelques observations sur le mur est du bâtiment, visible depuis l'esplanade du CNBDI.

La préoccupation première de l'étude était d'identifier les aménagements et les remaniements subis par les parements, en attachant une attention particulière aux baies 
et aux niveaux de plancher du MUR 100. La face orientale de ce mur donnait sur l'intérieur d'un bâtiment d'ampleur inconnue, mais dont le retour d'angle septentrional semble subsister à l'aplomb de l'escalier droit en béton aménagé dans le prolongement d'un escalier monumental de l'époque moderne, construit derrière la cour.

L'analyse complémentaire du MUR 100 a aussi permis de localiser du côté ouest plusieurs trous de plancher qui recoupent les ouvertures anciennes et plusieurs ancrages de solins de toiture. Pour le moment, il n'est pas possible de rattacher ces traces à une phase particulière de la construction, si ce n'est qu'elle est antérieure à la phase industrielle du site.

Du côté oriental, le revers des ouvertures mises au jour par Marie-Êve Scheffer a été retrouvé dans un parement de moellons très soigneusement taillés, conservé sur une plus grande surface que de l'autre côté. Curieusement, les niveaux de plancher identifiables ne coïncident pas exactement avec les seuils des ouvertures. C'est particulièrement le cas pour la porte en plein-cintre de l'étage dont le seuil se trouverait une assise sous le ressaut de plancher, sans qu'aucune reprise ne soit visible (Fig. $\mathrm{n}^{\circ} 1$ : Le parement intérieur (est) du mur oriental de la pièce identifiée comme l'infirmerie de l'abbaye de Saint-Cybard (MUR 100).).

Vers le nord, l'appareil s'interrompt sur un long « chaînage » qui parcourt le parement de bas en haut et dont on retrouve des traces jusque dans la salle voûtée du rez-de-chaussée. Cette maçonnerie ne semble pas être un angle de bâtiment, mais plus probablement une succession de piédroits de portes, peut-être révélateurs de la présence d'une cage d'escalier.

Enfin, l'observation de la partie inférieure du second mur, du côté du CNBDI, a mis en évidence deux travées de l'aile ouest du cloître. Celles-ci viennent se plaquer contre des constructions antérieures qui formaient un angle à l'emplacement de la travée d'angle nord-ouest du cloître.

Le traitement des relevés et leur mise en corrélation avec l'étude de Marie-Êve Scheffer permettra de comprendre davantage l'organisation de l'espace de l'abbaye entre la cour et le cloître.

CHAILLOU Mélanie

\section{ANNEXES}


Fig. $\mathrm{n}^{\circ} 1$ : Le parement intérieur (est) du mur oriental de la pièce identifiée comme l'infirmerie de l'abbaye de Saint-Cybard (MUR 100).

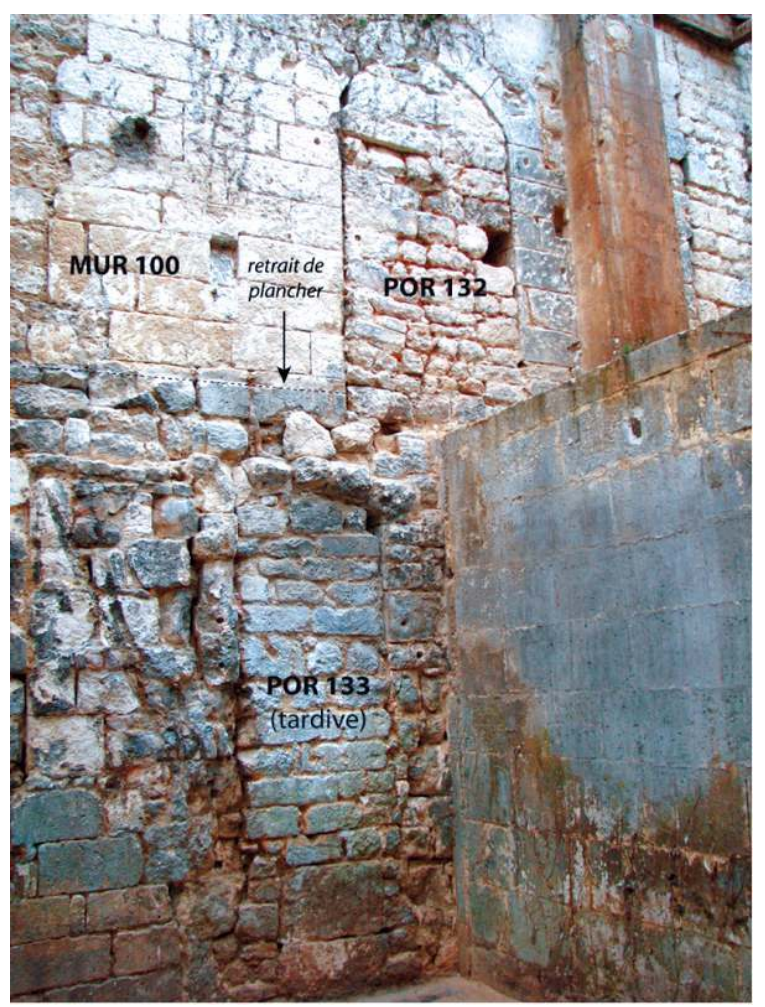

Auteur(s) : Chaillou, Mélanie (HADES). Crédits : Chaillou M., HADES (2008)

INDEX

operation Expertise (EX)

Thèmes : abbaye, cloître, cour, destruction, escalier, mur, ouverture, parement Index géographique : Poitou-Charentes, Charente (16), Angoulême

Index chronologique : IXe siècle apr. J.-C., Moyen Âge, Temps Modernes, VIe siècle apr. J.-C., XIe siècle apr. J.-C., XIXe siècle apr. J.-C., XVe siècle apr. J.-C., XVIIe siècle apr. J.-C.

\section{AUTEURS}

MÉLANIE CHAILLOU

HADES 